\title{
Erratum zu: Meinel, Florian (2019): Vertrauensfrage. Zur Krise des heutigen Parlamentarismus
}

\section{Michael Koß}

Online publiziert: 7. April 2021

(C) Deutsche Vereinigung für Politikwissenschaft 2021

\section{Erratum zu:}

\section{Polit Vierteljahresschr 2020}

https://doi.org/10.1007/s11615-020-00222-w

Der Artikel Meinel, Florian (2019): Vertrauensfrage. Zur Krise des heutigen Parlamentarismus von Michael Koß wurde ursprünglich Online First ohne „Open Access" auf der Internetplattform des Verlags publiziert. Nach der Veröffentlichung in Band 61 Heft 2 [pp. 191-193] hatten sich die Autoren für eine „Open Access“-Veröffentlichung entschieden. Das Urheberrecht des Artikels wurde deshalb in ( $)$ Der/die Autor(en) 2020 geändert.

Open Access Dieser Artikel wird unter der Creative Commons Namensnennung 4.0 International Lizenz veröffentlicht, welche die Nutzung, Vervielfältigung, Bearbeitung, Verbreitung und Wiedergabe in jeglichem Medium und Format erlaubt, sofern Sie den/die ursprünglichen Autor(en) und die Quelle ordnungsgemäß nennen, einen Link zur Creative Commons Lizenz beifügen und angeben, ob Änderungen vorgenommen wurden.

Die in diesem Artikel enthaltenen Bilder und sonstiges Drittmaterial unterliegen ebenfalls der genannten Creative Commons Lizenz, sofern sich aus der Abbildungslegende nichts anderes ergibt. Sofern das betreffende Material nicht unter der genannten Creative Commons Lizenz steht und die betreffende Handlung nicht nach gesetzlichen Vorschriften erlaubt ist, ist für die oben aufgeführten Weiterverwendungen des Materials die Einwilligung des jeweiligen Rechteinhabers einzuholen.

Weitere Details zur Lizenz entnehmen Sie bitte der Lizenzinformation auf http://creativecommons.org/ licenses/by/4.0/deed.de.

Die Online-Version des Originalartikels ist unter https://doi.org/10.1007/s11615-020-00222-w zu finden.

Michael Koß $(\bowtie)$

Berlin, Deutschland

E-Mail: mkoss@leuphana.de 